\title{
Improved prediction of all-cause mortality by a combination of serum total testosterone and insulin-like growth factor I in adult men
}

\author{
Nele Friedrich ${ }^{\text {a,* }}$, Harald J. Schneider ${ }^{\text {b }}$, Robin Haring ${ }^{\text {a }}$, Matthias Nauck ${ }^{\text {a }}$, Henry Völzke ${ }^{\text {c, }}$ \\ Heyo K. Kroemer ${ }^{d}$, Marcus Dörr ${ }^{\mathrm{e}}$, Jens Klotsche ${ }^{\mathrm{f}}$, Caroline Jung-Sievers ${ }^{\mathrm{g}}$, David Pittrow ${ }^{\mathrm{h}}$,
} Hendrik Lehnert ${ }^{i}$, Winfried März ${ }^{j}$, Lars Pieper ${ }^{f}$, Hans-Ulrich Wittchen ${ }^{\mathrm{f}}$, Henri

Wallaschofski $^{\mathrm{a}, 1}$, Günter K. Stalla ${ }^{\mathrm{g}, 1}$

\author{
a Institute of Clinical Chemistry and Laboratory Medicine, Ernst Moritz Arndt University, Sauerbruchstraße NK, \\ D-17475 Greifswald, Germany \\ b Medizinische Klinik - Innenstadt, Ludwig-Maximilians-University of Munich, Ziemssenstr. 1, D-80336 \\ Munich, Germany \\ c Institute for Community Medicine, Ernst Moritz Arndt University, Sauerbruchstraße NK, D-17475 Greifswald, \\ Germany \\ d Institute of Pharmacology, Ernst Moritz Arndt University, Loeffler Str. 23 d, D-17475 Greifswald, Germany \\ e Department Internal Medicine B, Ernst Moritz Arndt University, Loeffler Str. 23 a, D-17475 Greifswald, \\ Germany \\ f Institute of Clinical Psychology and Psychotherapy, Technische Universitaet Dresden, Chemnitzer Str. 46, D- \\ 01187 Dresden, Germany \\ g Max Planck Institute of Psychiatry, Kraepelinstr. 2-10, D-80804 Munich, Germany \\ h Institute of Clinical Pharmacology, Fiedlerstrasse 27, Technische Universitaet Dresden, D-01307 Dresden, \\ Germany \\ i 1st Dept. of Medicine, University of Lübeck, Ratzeburger Allee 160, D-23538 Lübeck, Germany \\ j Synlab Medizinisches Versorgungszentrum Heidelberg GmbH, Wasserturmstraße 71, 69214 Eppelheim, \\ Germany
}

\begin{abstract}
Objective: Lower levels of anabolic hormones in older age are well documented. Several studies suggested that low insulin-like growth factor I (IGF-I) or testosterone levels were related to increased mortality. The aim of the present study was to investigate the combined influence of low IGF-I and low testosterone on all-cause mortality in men.
\end{abstract}

Methods and results: From two German prospective cohort studies, the DETECT study and SHIP, 3942 men were available for analyses. During 21,838 person-years of follow-up, 8.4\% $(n=330)$ of men died. Cox model analyses with age as timescale and adjusted for potential confounders revealed that men with levels below the 10th percentile of at least one hormone [hazard ratio (HR) 1.38 (95\% confidence-interval (CI) 1.06-1.78), $\mathrm{p}=0.02$ ] and two hormones [HR 2.88 (95\% CI 1.32-6.29), $\mathrm{p}<0.01$ ] showed a higher risk of all-cause mortality compared to men with non-low hormones. The associations became non-significant by using the 20th percentile as cut-off showing that the specificity increased with lower cut-offs for decreased hormone levels. The inclusion of both IGF-I and total testosterone in a mortality prediction model with common risk factors resulted in a significant integrated discrimination improvement of $0.5 \%$ (95\% CI $0.3-0.7 \%, p=0.03)$.

Conclusions: Our results prove that multiple anabolic deficiencies have a higher impact on mortality than a single anabolic deficiency and suggest that assessment of more than one anabolic hormone as a biomarker improve the prediction of all-cause mortality.

Keywords: IGF-I Testosterone Mortality Study of Health in Pomerania (SHIP) DETECT 


\section{Introduction}

Insulin-like growth factor I (IGF-I) and total testosterone are anabolic hormones involved in the aging process with a strong age-dependent decline in their concentration [1,2]. IGF-I, as the main mediator of the growth hormone actions, is involved in cell replication and proliferation, protein synthesis, as well as glucose and lipid metabolism [3]. Low IGF-I levels have recently been related to a broad range of morbidities including chronic obstructive pulmonary disease [3], osteoporosis [3], metabolic syndrome (MetS), or diabetes mellitus $[4,5]$, as well as overall mortality [6]. Testosterone represents the principal male sex hormone and is linked to the regulation of e.g. fertility, libido, muscle mass and glucose metabolism [7]. Low total testosterone levels have been associated with hypertension [7], insulin resistance [8], the MetS, and type 2 diabetes [9].

In addition to the associations with major co-morbidities, we recently have demonstrated that low levels of IGF-I [6] and total testosterone [10] were directly associated with increased risk of mortality in a population-based samples of men. In particular, men with either low IGF-I or total testosterone levels had an almost two-fold higher risk of all-cause mortality.

The impact of multiple low serum hormone concentrations, including IGF-I, total testosterone and dehydroepiandrosterone sulphate on mortality was investigated in two previous studies $[11,12]$. The InCHIANTI study [12] as well as a Polish study in men with chronic heart failure [11] reported that the risk of mortality constantly increases with the number of deficient hormones. However, both studies were limited by relatively small study populations of 410 [12] or 208 [11] men, respectively, and by a narrow age-range. Furthermore, these studies suggested that a combination of more than one hormone might be superior in the prediction of mortality. However, the quantification of the improvement in risk prediction by the combined biomarkers as one of the key questions has not been answered satisfactorily.

Therefore the objective of the present study was to verify the previously described association between the combination of low hormone levels and all-cause mortality based on IGF-I and total testosterone levels in a population of 4092 men aged 18-91 years from two studies. Furthermore, we examined whether the prediction of mortality on the basis of a model containing hormone levels is superior to a model with known risk factors.

\section{Materials and methods}

\subsection{Design and subjects}

DETECT (Diabetes Cardiovascular Risk-Evaluation: Targets and Essential Data for Commitment of Treatment) is a large, multistage, and nationally representative study in Germany [13]. On 16th and 18th September 2003, 3188 GPs completed a standardized assessment of the diagnostic and therapeutic profile of 55,518 unselected consecutive patients (59\% women and $41 \%$ men; over 17 years). These physicians were successfully recruited, meeting the recruitment criteria, namely enrolment from signature, completion of pre-study questionnaire, willingness to adhere to the complex laboratory and follow-up procedures. This constitutes a total initial response rate of $60.2 \%$ for the physicians. Further adjustments for non-response, regional distribution, and attrition were performed. Out of a total of $\mathrm{N}=55,518$ eligible patients at the target days, a random subsample of $\mathrm{N}=7519$ in 851 primary care settings additionally attended a standardized laboratory screening program and were part of 
the prospective component of DETECT. Of these patients, 6826 (2782 men and 4044 women) participated in a 1-year or 4-year follow-up which were conducted between September and December 2004 or 2007. It results in a patient response rate of $90.8 \%$. The study was approved by the ethics committee of the Technical University of Dresden (AZ:

EK149092003; date: September 16th, 2003). All patients gave written informed consent. Of the 2782 men, seven men were excluded due to missing information on time of death. Furthermore, 529 patients with missing data for IGF-I or total testosterone and 178 patients with missing data for used confounders were also excluded. Valid data were available in 2068 men. No differences regarding age, physical activity, waist- to-height ratio (WHtR), diabetes, and increased blood pressure were found between excluded men $(n=714)$ and men participated in the present study.

SHIP (Study of Health in Pomerania) is a longitudinal population- based cohort study in West Pomerania, a region in the northeast of Germany $[14,15]$. The total population of West Pomerania selected for SHIP comprised 212,157 inhabitants. A two-stage cluster sampling method adopted from the WHO MONICA Project Augsburg, Germany yielded 12 five-year age strata (20-79 years) for both genders, each including 292 individuals [16]. The sampling was performed from population registries, where all German citizens are registered. Data collection started in October 1997 and was finished in March 2001. The net sample (after exclusion of migrated or deceased persons) comprised 6267 eligible subjects. All subjects received a maximum of three written invitations. In cases of non-response, letters were followed by several phone calls or by home visits if contact by phone was not possible. Finally, 2116 men and 2192 women (response proportion 69\%) participated. All participants gave written informed consent. The study conformed to the principles of the Declaration of Helsinki as reflected by an a priori approval of the Ethics Committee of the University of Greifswald. Of the 2116 male participants 125 subjects with missing data for IGF-I or total testosterone and 117 patients with missing data for used confounders were excluded. Valid data including mortality follow-up were available in 1911 men. Excluded men $(n=242)$ were on average 4 years younger than men included in the analyses. However, no differences regarding the age-adjusted proportions/mean of smoking, physical activity, diabetes, increased blood pressure or WHtR were found.

\subsection{Instruments and measurements}

Information on age, sex, socio-demographic characteristics, and medical histories were assessed by standardised interviews and medical records by the primary care physicians in DETECT and by standardised computer-assisted personal interviews in SHIP. In both studies, physicians and study nurses were advised to measure weight, height, blood pressure, and waist circumference according to written, standardized instructions given in a manual. Smoking was categorised into smokers and non-smokers. Subjects who participated in physical training during summer or winter for at least two hour a week were classified as being physically active. A systolic and diastolic blood pressures of $>140$ and $>90 \mathrm{mmHg}$, respectively, were considered increased. Diabetes mellitus was defined as history of diabetes as reported by patients or physicians in DETECT and SHIP, respectively, intake of oral antidiabetic drugs or insulin, or hemoglobin A1c (HbA1c) levels P6.5\%. For both studies, we defined liver disease as physician's or self-reported diagnosis of liver disease or aspartateamino-transferase or alanin-aminotransferase $>$ population mean +2 standard deviation. Kidney failure was assumed if the estimated glomerular filtration rate (GFR) using the Modification of Diet in Renal Disease (MDRD) formula was $<30 \mathrm{ml} / \mathrm{min}$ [17]. Missing values in categorical variables were treated as separate group. 
In DETECT, blood samples were collected and shipped by courier at room temperature within $24 \mathrm{~h}$ to the central laboratory. Blood samples were taken either fasting or non-fasting and fasting state was recorded. Upon arrival in the central laboratory, the samples were centrifuged immediately and serum and plasma was stored at $-20{ }^{\circ} \mathrm{C}$ until further processing. In SHIP non-fasting blood samples were taken between 07:00 a.m. and 04:00 p.m., analysed immediately for routine clinical chemistry parameters and stored at $-80{ }^{\circ} \mathrm{C}$ for IGF-I and testosterone analyses. In both studies IGFI was determined with an automated chemiluminescence system (Nichols Institute Diagnostics, San Clemente, CA, USA). The analytical sensitivity was $6 \mathrm{ng} / \mathrm{ml}$. In SHIP, total testosterone levels were measured using competitive chemiluminescent enzyme immunoassays on an Immulite 2500 analyzer (Siemens Immulite 2500 DHEA-SO4, ref. L5KDS, lot 106; and Siemens Immulite 2500 Total Testosterone, ref. L5KTW, lot 110; Siemens Healthcare Diagnostics GmbH, Eschborn, Germany). The analytical sensitivity was $0.5 \mathrm{nmol} / \mathrm{l}$. In DETECT, total testosterone was determined with an electrochemiluminescence immunoassay (Modular analytics, Roche Diagnostics, Mannheim, Germany). The analytical sensitivity was $0.069 \mathrm{nmol} / \mathrm{l}$. Reagents and secondary standard were used as recommended by the manufacturer. Separately in DETECT and SHIP, low levels of IGF-I and total testosterone were defined according to the 10th, 15th, or 20th percentile in every 5-years age-group (Table A.1).

\subsection{Statistical analysis}

Categorical data were expressed as percentages; continuous data were expressed as mean (standard deviation). Bivariate statistic was performed with $\chi 2$ test for categorical variables and Mann- Whitney-U-test for continuous distributions. Multivariable Cox proportional hazard regression models with age as timescale were run to assess the associations between low hormone levels and all cause mortality. The full models were adjusted for WHtR, smoking, physical activity, diabetes, liver diseases, increased blood pressure, and highsensitive C-reactive protein. A sensitivity analysis was performed after the exclusion of men with a GFR $<30 \mathrm{ml} / \mathrm{min}$. The model assumption for the Cox proportional hazards regression model was checked with Schoenfeld residuals and $\log$ of the negative log of survival plots. Hazard ratios (HR) with 95\% confidence intervals (CI) were calculated. Furthermore, we estimated the integrated discrimination improvement (IDI) to examine whether the prediction on the basis of a model without IGF-I or testosterone was significantly improved after inclusion of both hormones as continuous parameters [18]. In contrast to the net reclassification improvement which needs a priori meaningful predicted risk categories, the integrated discrimination improvement is based on continuous differences in the predicted risk from new and old models. IDI were obtained with logistic regression models that examined deaths through 4 years of follow-up, which was available for 3336 participants. Moreover, the corresponding areas under the curve (AUC) were calculated and compared as well as receiver-operating-characteristic (ROC) curves were plotted for model with and without IGF-I and testosterone. A value of $p<0.05$ was considered statistically significant. Statistical analyses were performed with SAS 9.1 and 9.2 (SAS Institute Inc., Cary, NC, USA) and Stata 9 (Stata Corporation, College Station, TX).

\section{Results}

\subsection{General characteristics}

Comparisons regarding general baseline characteristics are presented in Table 1. Men with one or two low hormone levels had a higher WHtR, were less physically active and more 
often affected by diabetes mellitus and liver diseases compared to men with non-low IGF-I and total testosterone levels, respectively. No differences in smoking habits were apparent between the different groups.

\subsection{Association of IGF-I and total testosterone levels to all-cause mortality}

During the 21,838 person-years (SHIP 15,299 person-years, DETECT 6538 person-years) of follow-up $8.4 \%(\mathrm{n}=330)$ of men died. The crude mortality rate ratios are given in Table 2 . Men with two hormones involved had, independently of the used categorization, higher crude rate ratios. Results of univariate Kaplan-Meier survival analysis (Fig. 1) also revealed that the decrease in cumulative survival was more evident in men with one $(\mathrm{p}<0.01)$ or two $(\mathrm{p}<$ 0.01-0.05) hormones with low levels compared to men with two non-low hormones.

These findings were confirmed by multivariable Cox regression analyses adjusted for WHtR, smoking, and physical activity. Men with one or both hormones below the 10th or 15th percentile had higher risks of all-cause mortality compared to men with two non-low hormones (Table 3). Furthermore, the mortality risk is higher for 2 low hormones compared to 1 low hormone which implies a dose-response relation. The additional inclusion of diabetes, liver disease, increased blood pressure, and high-sensitive C-reactive protein as confounders did not affect these results for the 10th percentile. However, in analyse using the 15th percentile as cut-off, only men with 2 low hormones had still a significant higher mortality risk. Therefore, the risk estimates and thus the specificity increased with lower cutoffs to define low levels of IGF-I and total testosterone.

Further factors which were significantly related to all-cause mortality (model with 10th percentile as cut-off for testosterone and IGF-I) were smoking [HR 2.41 (95\% CI 1.83-3.17), $\mathrm{p}<0.01$ ], diabetes [HR 1.45 (95\% CI 1.14-1.84), $\mathrm{p}<0.01$ ], liver disease [HR $2.26(95 \% \mathrm{CI}$ $1.52-3.38), \mathrm{p}<0.01$ ], increased blood pressure [HR 0.79 (95\% CI 0.63-0.99), $\mathrm{p}=0.04$ ], and high-sensitive C-reactive protein [per $10 \mathrm{mg} / \mathrm{l} \mathrm{HR} 1.16$ (95\% CI 1.08-1.24), p $<0.01$ ].

The exclusion of men with a GFR $<30 \mathrm{ml} / \mathrm{min}[\mathrm{n}=23$; one hormone $<10$ th percentile: HR 1.41 (95\% CI 1.09-1.82), $\mathrm{p}=0.01$; two hormones <10th percentile: HR 2.65 (95\% CI 1.14$6.18), \mathrm{p}=0.02]$, men who died within the first year of follow-up $[\mathrm{n}=34$; one hormone $<10$ th percentile: HR 1.42 (95\% CI 1.08-1.86), $\mathrm{p}=0.01$; two hormones $<10$ th percentile: HR 3.07 (95\% CI 1.34-7.03), $\mathrm{p}<0.01]$, or SHIP men who received androgen therapy (testosterone or other androgens), GH or any kind of anti-androgen therapy $[\mathrm{n}=4$; one hormone $<10$ th percentile: HR 1.38 (95\% CI 1.06-1.78), $\mathrm{p}=0.02$; two hormones $<10$ th percentile: HR 2.88 (95\% CI 1.32-6.29), $\mathrm{p}<0.01$ ] did not change the results substantially. Moreover, we performed an additional analyse in the subgroup of men older than 60 years $(n=1805)$. Also these analyses showed that men with one [HR 1.41 (95\% CI 1.06-1.86), $\mathrm{p}=0.02$ ] or two [ $<10$ th percentile: HR 2.90 (95\% CI 1.24-6.79), $\mathrm{p}=0.01$ ] low hormone levels had a higher mortality risk.

After the inclusion of IGF-I and total testosterone to the standard model (with age, smoking, systolic blood pressure, diabetes, WHtR, total cholesterol, and HDL cholesterol as predictors), the discrimination slope increased from $9.42 \%$ to $9.92 \%$; resulting in an absolute IDI of $0.5 \%$ $(95 \%$ CI $0.3-0.7 \%, p=0.03)$ and a relative IDI of $5.3 \%$. AUC for the standard model was 0.809 and slightly increased to 0.811 after the inclusion of IGF-I and total testosterone as additional predictors $(\mathrm{p}=0.52)$. 


\section{Discussion}

In the present study we revealed that the mortality risk in adult men successively increases with the combination of low IGF-I and testosterone levels, independent of age and major confounders. This is in good agreement with previous results of the InCHIANTI study, a cohort study that investigated the relation of low levels of IGF-I, bioavailable testosterone, and dehydroepiandrosterone sulfate with mortality in 410 men 65 years or older [12]. In contrast to previous studies including the SHIP cohort [6,10], which revealed a higher allcause mortality in men with low IGF-I [6,19,20] or low total testosterone levels [10,21,22], in the InCHIANTI study low IGF-I or low bioavailable testosterone as single hormones were not related to mortality [12]. Small patient and event numbers (InCHIANTI 126 deaths vs. SHIP 359 deaths) might be explain the different findings.

Furthermore, the cut-off to define low free or total testosterone levels plays an important role as shown in Fig. 1. The InCHIANTI study used a higher value of $2.4 \mathrm{nmol} / 1$ (lowest quartile) to define low bioavailable testosterone levels as compared with current guidelines [23]. This cut-off might be too unspecific to detect an association between low testosterone levels and mortality as we show in our study population for the 20th percentile. A further study in 208 men with chronic heart failure, also investigating IGF-I and testosterone, similarly revealed decreasing survival rates with an increase in the number of low hormones [11]. Furthermore, each single hormone level was inversely related to mortality in this study. In contrast to former studies our present study population consisted of men who were not selected by age or according to a specific disease with per se increased mortality risk. Our cohort covered a broader age-range and included over 4000 men with 359 cases of death $[11,12]$.

Changes in IGF-I and testosterone levels due to the aging process are well documented. Both IGF-I and total testosterone levels significantly decline with age and thus it seems consequential that lower hormone levels are related to increased morbidity [3,24]. Whether IGF-I or total testosterone levels directly influence mortality, or represent biomarkers of underlying morbidity is still subject of debate. However, the concept that low levels of hormones may play an independent causal role in longevity, is not surprising. Multisystemic disorders that are widely prevalent in aging subjects, such as the metabolic syndrome, frailty syndrome, and chronic heart failure, are more likely associated with multiple hormonal dysregulation rather than a single hormonal derangement $[11,25]$. There is increasing evidence that aging or subclinical diseases are associated with a decline in hormones and increase in catabolic hormones [26]. Therefore, hormonal deficiency might be a surrogate parameter of disease severity, especially in men. In face of the present findings, it was beyond the scope of our study to analyze if the association of hormonal dysregulation with increased mortality is also present for other non-anabolic hormones such as, for example, thyroid hormone levels. Even though, an analysis of the SHIP cohort revealed no independent association of thyrotropin levels with mortality [27], further studies are needed for a conclusive answer. In face of the fact that we used age-specific low hormone levels it is arguable to break the problem only down to the aging process. One possible, but clearly theoretical, explanation might be a complex interaction between genetic background, individual risk behaviour and hormone regulation. Several genome-wide association studies showed that genetic variants of the fat mass- and obesity-associated gene (FTO) are related to obesity $[28,29]$, which in turn represents a major cause for low testosterone levels in men. Furthermore, another investigation on the SHIP collective revealed that the FTO risk alleles were associated with lower IGF-I levels independently of obesity [30]. Moreover, obesity and the FTO gene are associated with an abnormal glucose metabolism as well as cardiovascular disease in men and therefore, are risk factors for mortality [31]. All these facts contribute to 
the complex interplay between hormone regulation and mortality. However the present study has, due to its epidemiological design, not the ability to clarify specific pathways which explain the presence of both low IGF-I and testosterone levels and their relation to a higher mortality.

The ongoing discovery of new biomarkers presents opportunities and challenges for biostaticians and clinicians to evaluate and judge these new biomarkers and to develop new risk models for a more individualized medical approach. Therefore we estimated the IDI to examine whether the prediction of all-cause mortality by a combination of both hormones is superior. In the present study, the estimates of IDI suggest that the addition of IGF-I and total testosterone to the model with established mortality risk factors did significantly improve the discriminatory property of the prediction model. However, the improvement was low.

The aim of our study was to verify the previously described association between the combination of low hormone levels and all-cause mortality based on low IGF-I and total testosterone levels in large setting. The analysed studies were conducted in the same country with the same health care system and covered a wide age-range. However, both studies based on different backgrounds (primary care and population-based) which results in differences with respect to e.g. age, WHTR, and proportion of diabetes or increased blood pressure (Table A.2). One further strength was the use of the same assay in both studies to measure IGF-I levels. Limitations might have arisen from the single determination of IGF-I or total testosterone which was measured only at baseline. Additionally, hormone levels may vary because of individual fasting or the time of day in particular for total testosterone. Blood samples were taken between 07:00 a.m. and 04:00 p.m., however, a previous investigation in SHIP showed only minor differences in total testosterone levels between serum samples drawn before and after noon [32], therefore, this variation is expected to be minimal. Furthermore, different assay systems to determine total testosterone were used (SHIP: Siemens Immulite 2500, DETECT: Roche Diagnostics) and the assays were not crosschecked between both studies. Therefore, low total testosterone levels were separately defined by percentiles in both studies. However, analyses using the overall 10th percentile to define low hormone levels confirmed our main results (Table A.3). A further limitation arise from the missing measurement of sex hormone-binding globulin, therefore no calculation of the free and bioavailable testosterone was possible. Moreover, the follow-up in our study, particularly in the DETECT study was rather short and less than $10 \%$ of all participants died during follow-up. Therefore we can only draw conclusions on early death and we do not know if our findings extend to longer-term follow-up. Furthermore, analyses with causespecific mortality would further clarify the relation between multiple anabolic deficiencies and mortality. Unfortunately due to the small number of subjects with both low IGF-I and testosterone levels and inferential the low number of death in this group analyses with causespecific mortality were not realisable.

In conclusion, our results confirm former studies showing that multiple anabolic deficiencies have a higher impact on mortality than a single anabolic deficiency. Furthermore, the inclusion of both hormones, IGF-I and testosterone, did improve prediction models for allcause mortality including established risk markers in this study. Therefore our results suggest that assessment of more than one anabolic hormone as a biomarker improve the prediction of all-cause mortality in men in a population-based approach. 
Table 1

Badine duracteristics of subjects in the subgroups, by number of low hormone levels (cut-off: 15 percentile each)

\begin{tabular}{|c|c|c|c|c|}
\hline \multirow[t]{2}{*}{ Characteristics } & \multicolumn{4}{|c|}{ Number of low harmones } \\
\hline & $0(N-2885)$ & $1(N-965)$ & $2(N-92)$ & $p^{*}$ \\
\hline Age (years) & $55.7(15.1)$ & $560(15.1)$ & $559(150)$ & 0.37 \\
\hline Smoking $(x)$ & & & & 091 \\
\hline Smakers & 255 & 259 & 27.2 & \\
\hline Missing val ues & $a_{1}$ & $a_{2}$ & 0 & \\
\hline Physically active (X) & & & & $\infty 01$ \\
\hline$<$ h/week & 463 & 51.1 & 630 & \\
\hline WHtR & $056(007)$ & ass (008) & $061(007)$ & 801 \\
\hline Dishetes mellitus ( $x$ ) & 166 & 26.4 & 30.4 & $\$ 01$ \\
\hline Liver disease $(x)$ & 53 & 135 & 17.4 & 401 \\
\hline Increased blood pressure ( $x$ ) & 51.7 & 553 & 609 & 004 \\
\hline $\mathrm{IGH}(\mathrm{ng} / \mathrm{ml})$ & $146.3(480)$ & $1120(604)$ & $73.6(242)$ & 001 \\
\hline Total testasterone (nmolin) & $17.3(5.3)$ & $129(7.8)$ & 6.4 (3.9) & $\$ 01$ \\
\hline
\end{tabular}

WHER - waist-to-height ratio; ICF-I - insulin-like growth factor L Low hormone levels were defined acos rding to the age specific 15 th percentile

" $\chi 2$-test (nominal data) or Mann-Whitney test (interval data) were performed, categary "missing values" were not ind uded in tests-

Table 2

Crude all-cause mortality rate ratios by number of low hormone levels present (using 3 at-off, at 10,15 , and 20 percentile),

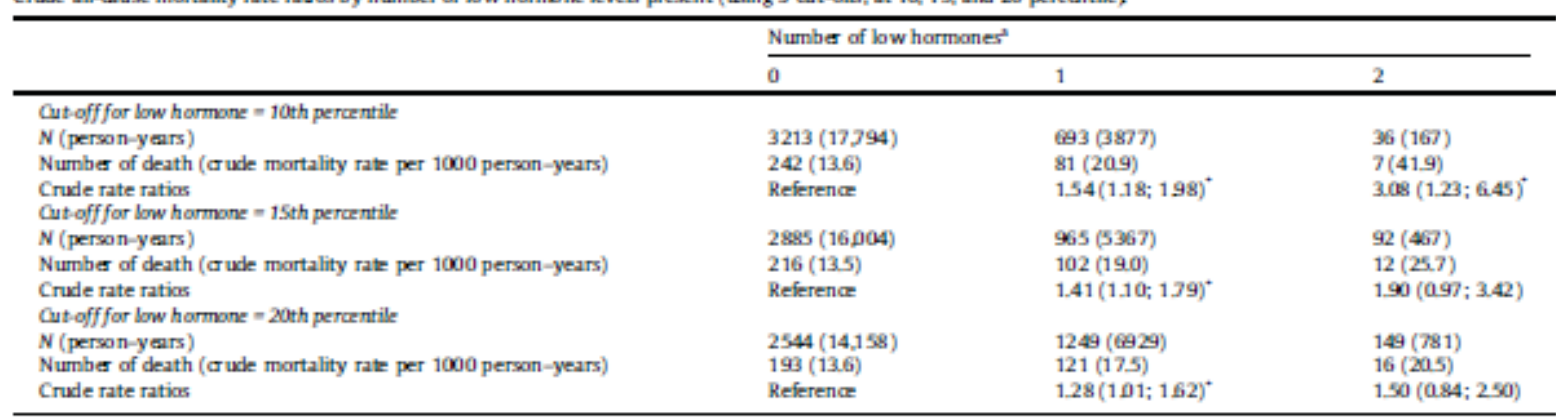

* $p<0.05$. Low hormone levels were defined according to the age-spedific 10 th, $15^{\text {th }}$, or 20 th percentile.

${ }^{2}$ Insulin-like growth factor I (GF-I) and total testasterone were cansidered.

Table 3

Assodition between low levels of $\mathrm{MCF}$ as well as total testosterone and all-cause morality.

\begin{tabular}{|c|c|c|c|c|}
\hline & \multicolumn{4}{|c|}{ Number of kow harmone levels (referenc: 0$)^{\mathrm{p}}$} \\
\hline & \multicolumn{2}{|l|}{1} & \multicolumn{2}{|l|}{2} \\
\hline & HR $(95 \% \mathrm{CI})$ & $p$ & $\mathrm{HR}(95 \% \mathrm{~d})$ & $p$ \\
\hline \multicolumn{5}{|l|}{ Cut-off for low harmane $=$ shudy-sperific 10th percentile } \\
\hline Moded 1: unadjusted & $1.60(1.24 ; 206)$ & $\infty 01$ & $3.13(1.44 ; 6.77)$ & $<001$ \\
\hline Moded 2: adjusted for WHtR, smoking, and physical activity & $1.54(1.20 ; 1.99)$ & $\$ 01$ & $3.20(1.47 ; 6.98)$ & $<001$ \\
\hline $\begin{array}{l}\text { Modd 3: adjusted for modd 2+diabetes, liver diseases, increased BP, and hs CRP } \\
\text { Cut-off for low harmane = study-sperific 1Sth percertile }\end{array}$ & \multicolumn{3}{|c|}{ Cut-off for bow harmone = study-sperific 1Sth percentile } & $<001$ \\
\hline Moded 1: unadjusted & $139(1.10 ; 1.76)$ & $\$ 01$ & $2.13(1.18 ; 3.85)$ & 001 \\
\hline Moded 2: adjusted for WHtR, smoking, and physical activity & $1.35(1.06 ; 1.71)$ & 0.01 & $2.10(1.15 ; 3.82)$ & 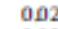 \\
\hline Modd 3: adjusted for modd 2+diabetes, liver diseases, increased BP, and hsCRP & $1.17(0.92 ; 1.50)$ & 0.20 & $1.95(1.07 ; 3.55)$ & 003 \\
\hline \multicolumn{5}{|l|}{ Cut-aff for bow harmane = shudy-sperific 20th percertile } \\
\hline Moded 1: unadjusted & $1.25(0.99 ; 1.57)$ & 0.06 & $1.74(1.04 ; 2.91)$ & 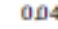 \\
\hline Moded 2: adjusted for WHtR, smoking, and physical activity & $1.20(0.96 ; 1.52)$ & a.11 & $1.73(1.03 ; 2.92)$ & 004 \\
\hline Moded 3: adjusted for model $2+$ diabetes, liver diseases inceased BP, and ho CRP & $1.03(0.81 ; 1.30)$ & 0.83 & $1.62(096 ; 2.74)$ & 007 \\
\hline
\end{tabular}

HR - hazard ratio; Q - confidence interval; WHtR = waist-to-height ratia; BP = blood pressure; hscRP = high-sensitive C-reactive protein.

a Insulin-like growth factor I(KGF-I) and total testasterone were corsidered as anabolic hormones. Multivariable Cax proportianal hazard regression models with age as timescale. 

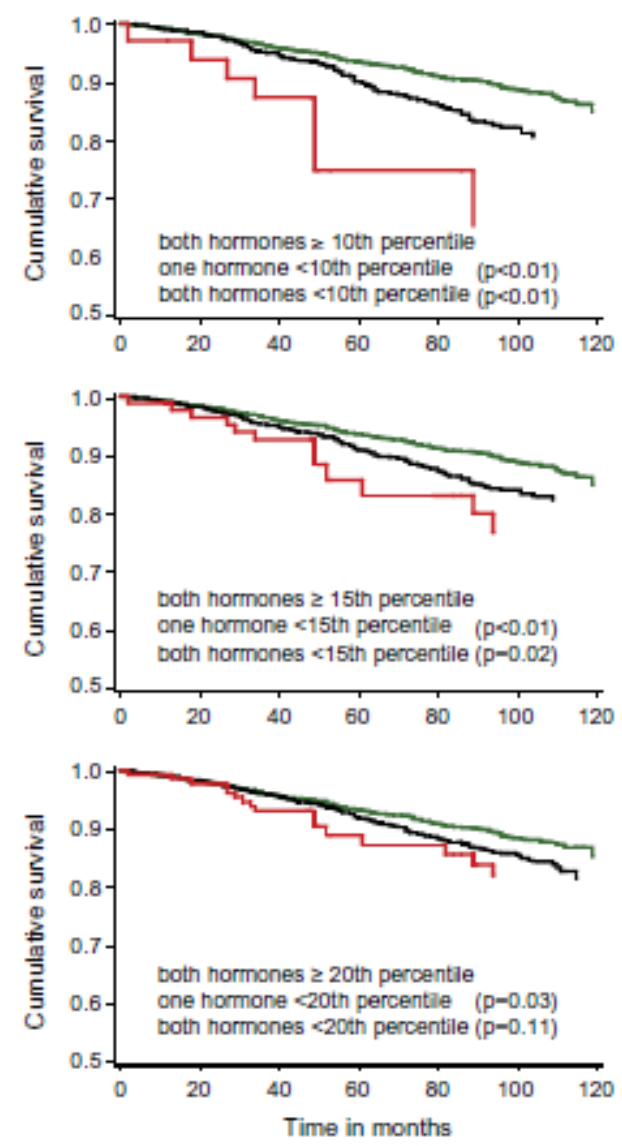

Fig 1. Estimated survival (Kaplan-Meier) by low levels of insulin-like growth factor 1 (ICF I) and total testosterone using varying cut-off at 10 th, $15^{\text {the }}$, and 20 th percentiles:

\section{Conflict of interest}

We declare that we have no conflicts of interest.

\section{Acknowledgements}

SHIP: This work is part of the research project Greifswald Approach to Individualized Medicine (GANI_MED). The GANI_MED consortium is funded by the Federal Ministry of Education and Research and the Ministry of Cultural Affairs of the Federal State of Mecklenburg - West Pomerania (03IS2061A). SHIP is part of the Community Medicine Net (http://www.medizin.uni-greifswald. de/icm) of the University of Greifswald, which is funded by grants from the German Federal Ministry of Education and Research (BMBF, Grant 01ZZ96030, 01ZZ0701); the Ministry for Education, Research, and Cultural Affairs; and the Ministry for Social Affairs of the Federal State of Mecklenburg-West Pomerania. Novo Nordisc and Pfizer provided partial grant support for the determination of serum samples and data analysis.

DETECT: Diabetes Cardiovascular Risk-Evaluation: Targets and Essential Data for Commitment of Treatment (DETECT) is a cross-sectional and prospective, longitudinal, nationwide clinical epidemiological study. DETECT is supported by an unrestricted educational grant from Pfizer GmbH, Karlsruhe, Germany. Members of the DETECT-Study group include: Principal investigator: Professor Dr. H.-U. Wittchen; Staff members: Dipl.- 
Psych. L. Pieper, Dipl.- Math. J. Klotsche, Dr. T. Eichler, Dr. H. Glaesmer, E. Katze. Steering Committee: Professor Dr. H. Lehnert (Lübeck), Professor Dr. G. K. Stalla (München), Professor Dr. A. M. Zeiher (Frankfurt); Advisory Board: Professor Dr. W. März (Heidelberg/Graz), Professor Dr. S. Silber (München), Professor Dr. Dr. U. Koch (Hamburg), Prof. Dr. D. Pittrow (München/Dresden), Professor Dr. M. Wehling (Mannheim), Dr. D. Leistner (Frankfurt), Priv.-Doz. Dr. H. J. Schneider (München), Dr. C. Sievers (München).

\section{Appendix A. Supplementary data}

Supplementary data associated with this article can be found, in the online version, at doi:10.1016/j.steroids.2011.10.005.

\section{References}

[1] Anversa P. Aging and longevity: the IGF-1 enigma. Circ Res 2005;97:411-4.

[2] Bartke A, Chandrashekar V, Dominici F, Turyn D, Kinney B, Steger R, Kopchick JJ. Insulin-like growth factor 1 (IGF-1) and aging: controversies and new insights. Biogerontology 2003;4:1-8.

[3] Juul A. Serum levels of insulin-like growth factor I and its binding proteins in health and disease. Growth Horm IGF Res 2003;13:113-70.

[4] Sandhu MS, Heald AH, Gibson JM, Cruickshank JK, Dunger DB, Wareham NJ. Circulating concentrations of insulin-like growth factor-I and development of glucose intolerance. A prospective observational study. Lancet 2002;359:1740-5.

[5] Wallander M, Brismar K, Ohrvik J, Ryden L, Norhammar A. Insulin-like growth factor I: a predictor of long-term glucose abnormalities in patients with acute myocardial infarction. Diabetologia 2006;49:2247-55.

[6] Friedrich N, Haring R, Nauck M, Lüdemann J, Rosskopf D, Spilcke-Liss E, Felix SB, Dörr M, Brabant G, Völzke H, Wallaschofski H. Mortality and serum insulinlike growth factor (IGF)-I and IGF binding protein 3 concentrations. J Clin Endocrinol Metab 2009;94:1732-9.

[7] Kaufman JM, Vermeulen A. The decline of androgen levels in elderly men and its clinical and therapeutic implications. Endocr Rev 2005;26:833-76.

[8] Nettleship JE, Jones RD, Channer KS, Jones TH. Testosterone and coronary artery disease. Front Horm Res 2009;37:91-107.

[9] Haring R, Volzke H, Felix SB, Schipf S, Dorr M, Rosskopf D, Nauck M, Schofl C, Wallaschofski H. Prediction of metabolic syndrome by low serum testosterone levels in men: results from the Study of Health in Pomerania. Diabetes 2009;58:2027-31.

[10] Haring R, Volzke H, Steveling A, Krebs A, Felix SB, Schofl C, Dorr M, Nauck M, Wallaschofski $\mathrm{H}$. Low serum testosterone levels are associated with increased risk of mortality in a population-based cohort of men aged 20-79. Eur Heart J 2010; Feb 17 [Epub ahead of print].

[11] Jankowska EA, Biel B, Majda J, Szklarska A, Lopuszanska M, Medras M, Anker SD, Banasiak W, Poole-Wilson PA, Ponikowski P. Anabolic deficiency in men with chronic heart failure: prevalence and detrimental impact on survival. Circulation 2006;114:1829-37.

[12] Maggio M, Lauretani F, Ceda GP, Bandinelli S, Ling SM, Metter EJ, Artoni A, Carassale L, Cazzato A, Ceresini G, Guralnik JM, Basaria S, Valenti G, Ferrucci L. Relationship between low levels of anabolic hormones and 6-year mortality in older men: the aging in the Chianti Area (InCHIANTI) study. Arch Intern Med 2007;167:2249-54. 
[13] Wittchen HU, Glaesmer H, Marz W, Stalla G, Lehnert H, Zeiher AM, Silber S, Koch U, Bohler S, Pittrow D, Ruf G. Cardiovascular risk factors in primary care: methods and baseline prevalence rates-the DETECT program. Curr Med Res Opin 2005;21:619-30.

[14] John U, Greiner B, Hensel E, Ludemann J, Piek M, Sauer S, Adam C, Born G, Alte D, Greiser E, Haertel U, Hense HW, Haerting J, Willich S, Kessler C. Study of Health In Pomerania (SHIP): a health examination survey in an east German region: objectives and design. Soz Praventivmed 2001;46:186-94.

[15] Völzke H, Alte D, Schmidt CO, Radke D, Lorbeer R, Friedrich N, Aumann N, Lau K, Piontek M, Born G, Havemann C, Ittermann T, Schipf S, Haring R, Baumeister SE, Wallaschofski H, Nauck M, Frick S, Arnold A, Junger M, Mayerle J, Kraft M, Lerch MM, Dörr M, Reffelmann T, Empen K, Felix SB, Obst A, Koch B, Glaser S, Ewert R, Fietze I, Penzel T, Dören M, Rathmann W, Haerting J, Hannemann M, Ropcke J, Schminke U, Jürgens C, Tost F, Rettig R, Kors JA, Ungerer S, Hegenscheid K, Kühn JP, Kühn J, Hosten N, Puls R, Henke J, Gloger O, Teumer A, Homuth G, Völker U, Schwahn C, Holtfreter B, Polzer I, Kohlmann T, Grabe HJ, Rosskopf D, Kroemer HK, Kocher T, Biffar R, John U, Hoffmann W. Cohort Profile: The Study of Health in Pomerania. Int J Epidemiol.

[16] Keil U, Stieber J, Doring A, Chambless L, Hartel U, Filipiak B, Hense HW, Tietze M, Gostomzyk JG. The cardiovascular risk factor profile in the study area Augsburg. Results from the first MONICA survey 1984/85. Acta Med Scand 1988;728:119-28.

[17] Levey AS, Bosch JP, Lewis JB, Greene T, Rogers N, Roth D. A more accurate method to estimate glomerular filtration rate from serum creatinine: a new prediction equation.

Modification of Diet in Renal Disease Study Group. Ann Intern Med 1999;130:461-70.

[18] Pencina MJ, D'Agostino Sr RB, D'Agostino Jr RB, Vasan RS. Evaluating the added predictive ability of a new marker: from area under the ROC curve to reclassification and beyond. Stat Med 2008;27:157-72. Discussion 207-12.

[19] Laughlin GA, Barrett-Connor E, Criqui MH, Kritz-Silverstein D. The prospective association of serum insulin-like growth factor I (IGF-I) and IGF-binding protein-1 levels with all cause and cardiovascular disease mortality in older adults: the Rancho Bernardo Study. J Clin Endocrinol Metab 2004;89:114-20.

[20] Roubenoff R, Parise H, Payette HA, Abad LW, D'Agostino R, Jacques PF, Wilson PW, Dinarello CA, Harris TB. Cytokines, insulin-like growth factor 1, sarcopenia, and mortality in very old community-dwelling men and women: the Framingham Heart Study. American J Med 2003;115:429-35.

[21] Khaw KT, Dowsett M, Folkerd E, Bingham S, Wareham N, Luben R, Welch A, Day N. Endogenous testosterone and mortality due to all causes, cardiovascular disease, and cancer in men: European prospective investigation into cancer in Norfolk (EPIC-Norfolk) Prospective Population Study. Circulation 2007;116:2694-701.

[22] Laughlin GA, Barrett-Connor E, Bergstrom J. Low serum testosterone and mortality in older men. J Clin Endocrinol Metab 2008;93:68-75.

[23] Bhasin S, Cunningham GR, Hayes FJ, Matsumoto AM, Snyder PJ, Swerdloff RS, Montori VM. Testosterone therapy in men with androgen deficiency syndromes: an Endocrine Society clinical practice guideline. J Clin Endocrinol Metab 95:2536-2559. [24] Landin-Wilhelmsen K, Lundberg PA, Lappas G, Wilhelmsen L. Insulin-like growth factor I levels in healthy adults. Horm Res 2004;62(Suppl 1):8-16.

[25] Cappola AR, Xue QL, Fried LP. Multiple hormonal deficiencies in anabolic hormones are found in frail older women: the Women's Health and Aging studies. J Gerontol A Biol Sci Med Sci 2009;64:243-8.

[26] Lamberts SW, van den Beld AW, van der Lely AJ. The endocrinology of aging. Science 1997;278:419-24. 
[27] Ittermann T, Haring R, Sauer S, Wallaschofski H, Dorr M, Nauck M, Volzke H.

Decreased serum TSH levels are not associated with mortality in the adult northeast German population. Eur J Endocrinol 2010;162:579-85.

[28] Frayling TM, Timpson NJ, Weedon MN, Zeggini E, Freathy RM, Lindgren CM, Perry JR, Elliott KS, Lango H, Rayner NW, Shields B, Harries LW, Barrett JC, Ellard S, Groves

CJ, Knight B, Patch AM, Ness AR, Ebrahim S, Lawlor DA, Ring SM, Ben-Shlomo Y, Jarvelin MR, Sovio U, Bennett AJ, Melzer D, Ferrucci L, Loos RJ, Barroso I, Wareham NJ, Karpe F, Owen KR, Cardon LR, Walker M, Hitman common variant in the FTO gene is associated with body mass index and predisposes to childhood and adult obesity. Science 2007;316:889-94.

[29] Scuteri A, Sanna S, Chen WM, Uda M, Albai G, Strait J, Najjar S, Nagaraja R, Orru M, Usala G, Dei M, Lai S, Maschio A, Busonero F, Mulas A, Ehret GB, Fink AA, Weder AB, Cooper RS, Galan P, Chakravarti A, Schlessinger D, Cao A, Lakatta E, Abecasis GR. Genome-wide association scan shows genetic variants in the FTO gene are associated with obesity-related traits. PLoS Genet 2007;3:e115.

[30] Rosskopf D, Schwahn C, Neumann F, Bornhorst A, Rimmbach C, Mischke M, Wolf S, Geissler I, Kocher T, Grabe HJ, Nauck M, Hebebrand J, Kroemer HK, Friedrich N, Volzke H, Wallaschofski $\mathrm{H}$. The growth hormone-IGF-I axis as a mediator for the association between FTO variants and body mass index: results of the Study of Health in Pomerania. Int J Obes (Lond) 2011;35:364-72.

[31] Lappalainen T, Kolehmainen M, Schwab US, Tolppanen AM, Stancakova A, Lindstrom J, Eriksson JG, Keinanen-Kiukaanniemi S, Aunola S, Ilanne-Parikka P, Herder C, Koenig W, Gylling H, Kolb H, Tuomilehto J, Kuusisto J, Uusitupa M. Association of the FTO gene variant (rs9939609) with cardiovascular disease in men with abnormal glucose metabolism The Finnish Diabetes Prevention Study. Nutr Metab Cardiovasc Dis (in press).

[32] Friedrich N, Völzke H, Rosskopf D, Steveling A, Krebs A, Nauck M, Wallaschofski H. Reference ranges for serum dehydroepiandrosterone sulfate and testosterone in adult men. J Androl 2008;29:610-7. 